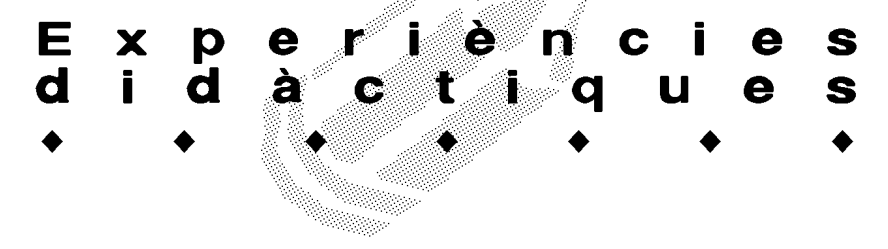

\title{
EL VOL D'EN PETER PAN. UNA EXPERIÈNCIA INTEGRADORA EN PSICOMOTRICITAT
}

\author{
Núria García Alsina. Mestra del CEIP de Pràctiques. Tarragona \\ Judit Vallvé Carbonell i Carme Sánchez Margalef. CEE Estela. Tarragona
}

\section{Introducció}

"Hi havia una vegada una sala molt gran on els nens jugaven amb coixins, matalassos, robes... Un dia el més decidit de tots va voler saltar del lloc més alt de la sala; per això es va posar una capa vermella i al crit de: «Sóc Superman!» va saltar.

Els seus amics varen pensar que aquell era un joc molt divertit i el van imitar.

Els nens que no sabien lligar-se la capa li demanaven a la «senyo» que els ajudés. Tant divertit era aquest joc que la «senyo" no parava de disfressar donant per suposat que totes les capes que volaven per la sala eren de Superman. Hi havia un nen que amb la seva capa vermella i enfilat dalt d'un gran cilindre es disposava a saltar...

La «senyo» el va animar dient-li: «Salta, Superman!». I el nen va girar-se i li va contestar: "Jo no sóc Superman! Jo sóc en Peter Pan!".

El nostre Peter Pan és un nen amb la síndrome de Down.

«Afavorir un desenvolupament harmoniós del nen és, per damunt de tot, donar-li la possibilitat d'existir com a persona única en el futur, és per tant oferir-li les condicions més favorables per a comunicar, expressarse, crear i pensar» (AUCOUTURIER, 1985).

El treball que presentem està basat en el projecte de col-laboració entre l'EEE Estela, el CEIP de Pràctiques i el Departament de Pedagogia de la URV en l'àrea de Didàctica de l'Expressió Corporal, que té com a objectiu poder donar una atenció més individualitzada i normalitzada als/les nens/es amb necessitats educatives especials, tal com queda reflectit en el Projecte Educatiu de Centre del CEIP de Pràctiques.

Aquest projecte està basat en el convenciment que tots els infants tenen el dret a rebre una educació individualitzada que els ajudi a superar les seves diferències i/o discapacitats, tot integrant-se en un ambient al més normalitzador possible.

\section{Aspectes teòrics de la pràctica psicomotriu}

El nostre projecte de treball està basat en el model metodològic de la Pràctica Psicomotriu Educativa de $\mathrm{B}$.
Aucouturier. Aquesta pràctica té com a objectiu afavorir i potenciar l'adaptació harmònica de la persona al seu entorn, mitjançant el treball sobre la seva pròpia identitat. Aquesta identitat es fonamenta i es manifesta a través del cos i aquest s'expressa mitjançant les relacions que estableix amb el temps, amb l'espai i amb els altres. (CAMPS, 1999). Parteix de la concepció del nen com a ésser global, intentant afavorir l'expressió de la totalitat corporal respectant cada individualitat.

La pràctica psicomotriu educativa no queda reduïda a proporcionar al nen/a una sèrie de coneixements específics i d'aprenentatges instrumentals; l'objectiu d'Aucouturier és el de posar el nen/a en una situació en què visqui emocionalment l'espai, els objectes, les relacions amb els altres... dins d'un marc precís i adequat, que adaptant-se al seu nivell maduratiu li permeti seguir evolucionant.

És una concepció de la psicomotricitat entesa no com un mitjà de desenvolupar habilitats motores exclusivament, sinó com un mitjà d'actuació en què s'utilitza el cos com a font d'aprenentatge per al nen/a, a través de les seves possibilitats de captar sensacions que transforma en percepcions i representacions, i possibilita que el nen/a entri en contacte amb el món que l'envolta.

És un plantejament psicomotriu que abandona les reeducacions localitzades, específiques i instrumentals per tenir en compte les potencialitats pròpies de cada nen/a, que es manifesten en cadascun dels seus actes. Per tant,es parteix del que té de positiu cada nen/a, del que ja sap fer oferint un model de treball que accepta la diversitat, respecta la manera de ser i el ritme d'aprenentatge de cada infant.

El model metodològic que presentem està basat en el treball de la globalitat partint del desig del nen i la nena, de la seva expressivitat psicomotriu i de la seva manera de comunicar-se, amb un projecte individualitzat per a cadascun d'ells. L'espai està organitzat per racons, utilitzant materials diversos i respectant l'itinerari escollit per cada nen/a, així com el temps de permanència en els diferents racons. (VISCARRO i FUGUET, 1996).

La sala de psicomotricitat és per al nen/a un lloc on desenvolupar-se amb plaer: 


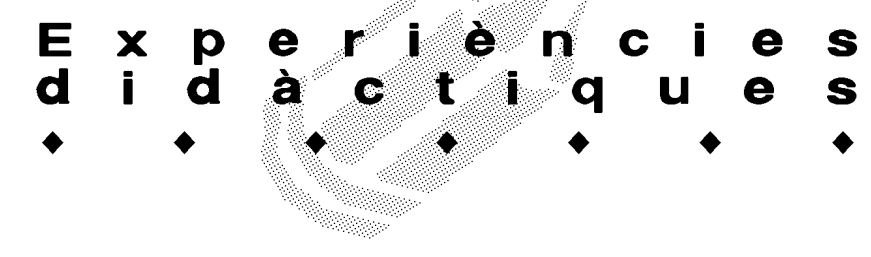

\section{El plaer de comunicar}

Si el nen/a viu el plaer de l'acció compartida amb els altres nens/es, es tornarà més obert a l'altre, podrà rebre i donar, serà capaç d'acceptar un punt de vista diferent al seu i d'estar menys centrat en ell mateix. Formar el nen en el plaer de comunicar és fer-lo sociable, però també ajudar-lo a sortir d'ell mateix.

\section{El plaer d'actuar i crear}

El nen/a és un ser d'impulsivitat motriu; aquesta impulsivitat és un motor de plaer de l'acció i l'únic mitjà de descàrrega emocional indispensable per al procés maduratiu del nen/a. El plaer de l'acció reforça el sentiment d'ésser ell mateix i, simultàniament crea la base de l'ésser responsable i creador. La creació afavoreix la descentralització, indispensable per a l'evolució del pensament del nen.

\section{El plaer de pensar}

És el plaer de l'activitat operatòria. La formació del pensament operatori necessita l'accés a aquesta descentralització amb la qual el nen/a s'allibera de les seves projeccions sensorials i motrius, afectives $\mathrm{i}$ imaginàries.

\section{Objectius del projecte}

L'objectiu general del Projecte de col-laboració CEE Estela i CEIP de Pràctiques és: Afavorir el desenvolupament global de la persona posant els nens/es en situació de compartir les diferències, per tal d'aprendre a valorar-les i respectar-les.
Els objectius específics són:

- Aprendre a conviure en la diversitat, acceptar-la i respectar-la en un ambient d'activitat lúdica.

- Utilitzar l'activitat motriu i el joc com una eina de comprensió i superació de les dificultats i la diferència.

- Donar sentit a les accions dels nens com a resultat de les emocions, conflictes, desitjos i necessitats.

- Facilitar l'aprenentatge significatiu dels continguts i objectius de l'àrea de Descoberta d'un mateix.

- Afavorir la pròpia experimentació psicomotriu en un espai diferent a l'habitual, més ric en recursos: humans i materials, i possibilitats d'acció.

- Compartir el joc motriu al costat dels altres nens /es del grup, l'observació, la imitació i, si és possible, la comunicació i la convivència.

- Ajudar el nen/a a obrir-se als altres adults que participen en la sessió, facilitant la seva autonomia personal envers el seu adult de referència.

- Oferir als nens/es amb necessitats educatives especials integrats en l'escola ordinària la possibilitat d'interactuar amb altres nens/es amb necessitats educatives similars.

- Possibilitar als nens/es la verbalització dels seus interessos, inquietuds, temors... davant la diversitat.

\section{Desenvolupament de l'activitat i metodologia}

Hem deixat el Peter Pan del nostre conte saltant

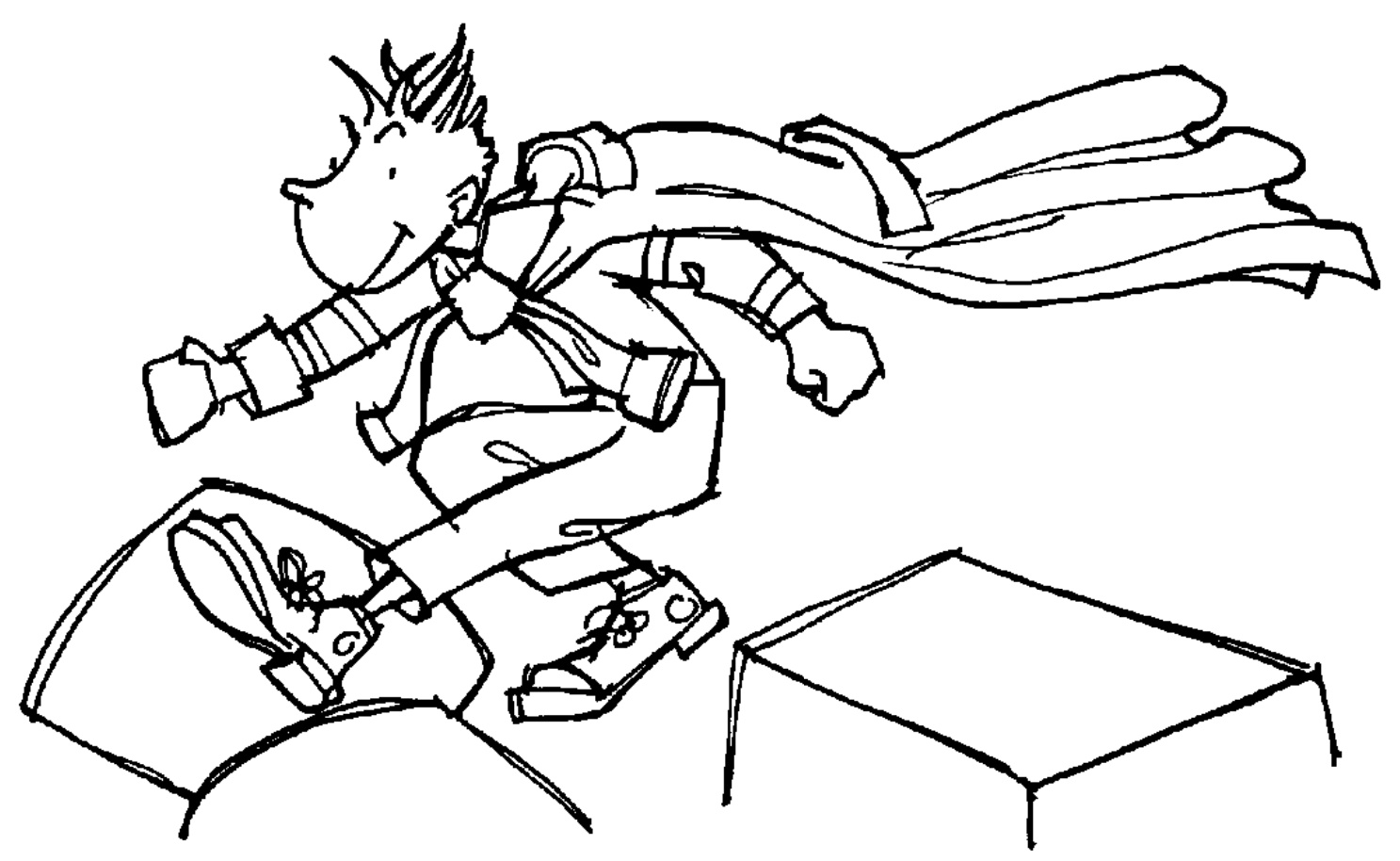




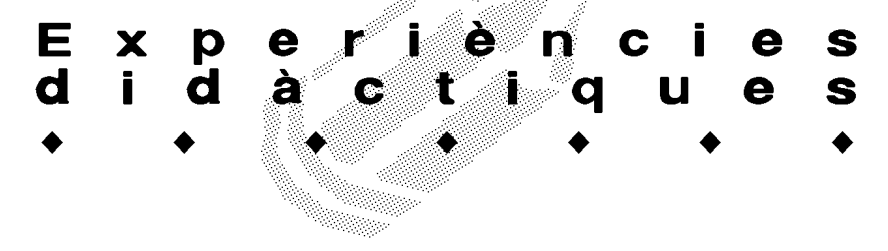

d'una torre molt alta i amb la seva resposta "Jo no sóc Superman, jo sóc en Peter Pan!", afirmant la seva individualitat. És aquest enfocament, el de treballar la diversitat des de la individualitat de cada nen/a, el que servirà de base a totes les activitats a realitzar en els diferents racons i en les diferents fases en què s'organitza cada sessió.

Els grups de referència amb els quals es feia aquesta activitat eren els dos nivells de $\mathrm{P} 5$ del CEIP de Pràctiques i el grup de nens/es més petits del CEE Estela, però sempre tenint en compte el nivell dels participants; creiem que aquests grups de referència es poden variar i ampliar aquesta participació als altres grups (P3 i P4). La tria de grups i participants es farà a l'inici del curs tenint en compte les necessitats dels nens matriculats en ambdós centres.

Les sessions de psicomotricitat estaran dividides en tres espais o racons on el nen/a realitzarà les diferents activitats lliurement.

\section{L'espai sensoriomotor}

En aquest espai s'afavoreix l'expressió, el desbloqueig del nen a través de jocs com caminar, córrer, saltar, lliscar per diferents superfícies, enfilar-se, rodolar, giravoltar... amb l'objectiu que el nen prengui consciència del seu cos $i$ assoleixi diverses habilitats. En aquesta dinàmica de plaer el nen/a analitza globalment i sintèticament els paràmetres exteriors i hi adapta la seva gestualitat. La seva reacció es manifesta en el control del cos i lentament en l'adquisició i l'elaboració de l'esquema corporal.

\section{L'espai del joc simbòlic}

Mitjançant jocs com disfressar-se o jugar a ser diferents personatges, els nens i nenes ens manifesten la seva emoció, els seus gestos, la seva postura, la mímica, la utilització de l'espai, dels objectes i del temps. Els objectes a utilitzar són: coixins d'escuma, robes, mocadors, anelles, pilotes... La capacitat de simbolització del nen el porta a utilitzar aquests objectes reals $\mathrm{i}$ transformar-los en objectes simbòlics. D'aquesta manera i des del punt de vista de desenvolupament psicomotor, d'una manera global queda treballada la coordinació òculo-manual; l'organització perceptiva, amb les operacions que poden realitzar sobre els objectes: classificar, seriar, ordenar... Aquest tipus d'operacions garanteixen el desenvolupament del pensament operatori.

\section{L'espai de representació}

Les activitats de representació ajuden el nen a construir el pensament operatori. Aquestes activitats permeten al nen prendre distància de les vivències sensoriomotrius i afectives i traslladar-les a un pla més racional, es a dir, a una òptica cognitiva. Els materials a emprar són: fustes, plastilina o fang, llapis, retoladors, guixos de colors per a dibuixar bé a la pissarra o bé al paper.

\section{Avaluació}

Inicial. Primerament es realitzarà una valoració de les necessitats educatives de tots els participants per part de les psicomotricistes d'ambdues escoles, per tal d'adequar les propostes d'activitats a les seves possibilitats. S'elaborarà una pauta d'observació on també quedaran reflectides totes les informacions sobre el desenvolupament psicomotriu aportades per les famílies en l'historial familiar.

Sumativa. Al llarg del curs s'aniran realitzant observacions de l'activitat del nen/a que s'aniran afegint a la pauta d'observació inicial. Es prepararan activitats en els racons que afavoreixin l'avaluació de les competències psicomotrius dels alumnes, d'acord amb els objectius de l'Àrea de Descoberta d'un mateix marcats en el Projecte Curricular de Centre. Amb els resultats de les observacions es programaran activitats que afavoreixin la pràctica d'aquelles competències psicomotrius on els/les alumnes tinguin més dificultat. Alhora s'analitzarà l'evolució de l'experiència per tal d'introduir-hi els canvis necessaris si es considera oportú.

Final. Amb totes les observacions realitzades al llarg del curs s'analitzarà l'evolució del nen/a i es reflectirà en l'informe que es lliura a les famílies al final de curs. Les professionals de les dues escoles analitzaran el desenvolupament de l'activitat al llarg del curs i dissenyaran els canvis necessaris per tal de millorar-la de cara al curs següent.

\section{Bibliografia consultada}

ARNAIZ, P. Fundamentación de la pràctica psicomotriz, en B. Aucouturier. Edit. Seco Olea. Madrid. 1988.

AUCOUTURIER, B. i altres. La pràctica psicomotriz. Reeducación y terapia. Edit. Científico - Médica. Madrid. 1985. AUCOUTURIER, B. Conferencia Lille. 1994.

CAMPS, C., VISCARRO, I. i ROTA, M. La actitud del educador en Psicomotricidad. «Psicomotricidad. Revista de Estudios y Experiencias», 61-62 (1999) 39-45.

EQUIP DE MESTRES CEE Estela-CEIP Pràctiques. Projecte de col.laboració entre l'Escola Estela i el CEIP Pràctiques. 2000.

VISCARRO, I. i FUGUET, J. Treballem la psicomotricitat a parvulari. "Comunicació Educativa», 9 (1996) 43-47.

VISCARRO, I. i CAMPS, M. Psicomotricidad: una experiencia de integración. Comunicació presentada al VI Congreso andaluz de Psicología de la actividad física i el deporte. Cadis. Novembre 1996. 